\title{
Sharing Economy: China's Opportunities, Challenges and Suggestions on Governance
}

\author{
Shucui Wang \\ Alibaba Business School \\ Hangzhou Normal University \\ Hangzhou, China \\ wangsc2003@126.com \\ Jianming Ma \\ Alibaba Business School \\ Hangzhou Normal University \\ Hangzhou, China \\ 1047898794@qq.com
}

\author{
Jiacen Suo \\ Alibaba Business School \\ Hangzhou Normal University \\ Hangzhou, China \\ maxsuo@stu.hznu.edu.cn \\ Jinjun $\mathrm{Yu}$ \\ Alibaba Business School \\ Hangzhou Normal University \\ Hangzhou, China \\ 2091491849@qq.com
}

\begin{abstract}
With the rapid development of the Internet, people have become participants and providers of personal goods exchanging and sharing. The development of sharing economy is of great importance to China, which is characterized by its relatively scarce per capita resources, abundant human resources and serious mismatch of resources. It also provides a good opportunity of "corner overtaking" for China's economy. This paper introduces the Transaction Cost Theory, the Collaborative Consumption Theory and new perspectives of sharing economy. After discussing the theoretical basis, research status and practices in China and other countries regarding the concepts of sharing economy, it points out the driving factors of the explosive growth of the sharing economy in light of China's national conditions and elaborates the challenges of the new-model sharing economy to China's social governance from four aspects. At the end of this paper, specific proposals on governing sharing economy are made, including the formulation of law and regulation, joint supervision with platforms, then enhancement of personal credit rating, social supervision and improvement of social security system.
\end{abstract}

Keywords-Sharing economy; Opportunities; Challenges; Governance

\section{INTRODUCTION}

With the rapid economic development, the society has changed from shortage to excess in terms of economy and structural changes have taken place in the efficiency of resource utilization. Not only there has been excess production capacity and inventory at the production end of enterprises, but there has also been a general excess of resources at the individual consumption end. With the rapid development of the Internet, people have become participants and providers of personal items exchanging and sharing. As a result, the phenomenon of sharing economy (or share economy) appears frequently in recent years. Through the Internet, mobile Internet and other information technologies, people have realized the full use of their personal idle goods and their added values. According to the "China's Annual Report on Shared
Economic Development 2018", China's transactions in the market of sharing economy in 2017 was approximately 4.9 trillion yuan, up by $47.2 \%$ from the previous year, and the number of people participating in service sector was approximately 70 million, an increase of 10 million over the previous year which indicates a remarkable result in stimulating employment. As an important part of sharing economy, the living service sector has a transaction volume of up to 1.3 trillion yuan, accounting for $26.9 \%$ of the whole economy, a year-on-year increase of $82.7 \%$ and shows a great potential. The development of sharing economy is of great importance to China, as China is characterized with its scarce per capita material resources, abundant human resources and serious mismatch of resources. It also provides a good opportunity for "corner overtaking". Whether China can seize the opportunity to properly deal with the challenges, brought by the rapid expansion of sharing economy to China's economic and social management or not lies in the modernization of the country's governance. How to regulate the development order of sharing economy is a prevailing research topic in the current public management field.

\section{THEORETICAL AND REFERENCE REVIEW}

\section{A. Transaction Cost Theory}

The Transaction Cost Theory was proposed by Coase who intuitively explained the phenomena of sharing economic[5]. The value of sharing economy lies in further eliminating information barriers to transactions through the Internet and reducing transaction costs, including search costs, contact costs and payment costs. Before the creation of shared platforms, these transactions could not be made because of excessively high transaction costs. Take the sharing transportation service as an example, the emergence of sharing transportation basically eliminates the search cost and guarantees the quality of service, thus creating an effective market with real supply and demand decisions[18]. Because of the reduction of such transaction costs, the private accommodation market, the 
private car market and the intermediary market have emerged and developed. To a certain extent, these markets have complemented or substituted the original market. The complementarity and substitution between the sharing economy and the traditional economy is the key to use the Transaction Cost Theory to understand the emergence and development of sharing economy.

\section{B. Collaborative Consumption Theory}

Collaborative consumption is another important theoretical support for sharing economy[11]. Collaborative Consumption Theory was proposed by Felson and Spaeth who defined it as the participation of many people and equal pay for equal work in terms of consumer goods or service[9]. In the following 30 years, there has been little research and application of cooperative consumption theory to explain sharing behavior until Russell Belk from University of York explained the concept of sharing based on this theory[1]. He thinks that sharing means the behavior and process of allocating the owners' resources to others or obtaining goods or services for my use from others. Collaborative consumption covers the areas such as donations, resales, transactions, loans, leases, gifts and exchanges. It collects fees and other forms of commissions by coordinating the acquisition and distribution of resources. As such exchange and consumption are based on the relations between individuals other than on the relationship between people and market. There is no need for ownership transfer. In this process, the relationship between people and things and the relations between people are redefined[4]. The existence of sharing economy makes occupying ownership cease to be the ultimate expression of consumers' desire and indicates that we may have entered a "post-ownership economy"[2], which Rifkin names "zero marginal cost society"[16]. Moreover, collaborative consumption has leaped over the value chain, realizing the redistribution of wealth among individual consumers and small service providers instead of relying on the necessary intermediate links. At the beginning of the 21 st century, with the popularity of the Internet, the logic based on "peer production" gradually evolved to the business form of sharing economy and the concept of sharing economy formed[3]. From 2011, "sharing economy" has been frequently concerned and discussed by the media of developed countries. In the same year, Times in the United States listed sharing economy among the top ten ideas that will change the world.

\section{Sharing Economy in the Internet Age}

Based on the Transaction Cost Theory and Collaborative Consumption Theory and combined with commercial practices in the Internet era, scholars have conducted further research on sharing economy and believe that sharing economy will bring new production models, consumption models and business operation model[23]. The sharing economy has become a new paradigm to revitalize stock, increase efficiency and enhance service[12]. Robin Chase, a sharing economy practitioner, has further analyzed the operating model of sharing economy based on the participants of sharing economy[17]. She believes that the sharing economy includes three participants: resource providers, resource requesters and economic sharing platforms from third-parties. Among them, the resource providers are the individuals or organizations that have idle resources and hope to profit by temporarily giving their usage rights of unused resources to others. Resource requesters are the individuals or organizations that have a demand for goods or services. These people or organizations often want their needs can be met as soon as possible. Third-party platforms can publish supply and demand information for both providers and demanders to coordinate and check both sides. They have obtained more trust in effectively matching the supply and demand sides and given a strong sense of security. But at the same time, Robin Chase also believes that the idea of "share for all" will redefine our understanding of assets and allow us to think again about regulation and management. Some Chinese scholars have raised some questions about China's model of sharing economy For example, the "platform + individuals" model, a new form of employment has not yet been identified by China's law. It is not clear whether all parties should assume their responsibilities or not, whether platform owners can only rely on continuous burning cash and price war to gain more market share or not. As China's personal credit assessment system has not yet completed and the lack of credit awareness among users at some platforms leads to a loss of trust in platforms and other users due to untrustworthy behaviors in market economic activities[19]. Such platforms have monopolistic advantages through giving subsidies to further enhance price monopolies and data monopolies[13], so they may not only set monopoly prices, but may also threaten data security. The sharing economy has provided opportunities for China to solve excess production capacity and meet the staggered needs. However, the above findings also indicate that China still faces a series of challenges in this field. How to retain the advantages of the sharing economy and effectively avoid the risks becomes the focus of this paper.

\section{DRIVING FACTORS FOR CHINA' S GROWTH IN THE SHARING ECONOMY}

\section{A. Unbalanced Private Possession of Materials}

With the continued prosperity of China's economy, China's Gini coefficient has exceeded the warning line of 0.4 for many years. The gap between the rich and the poor is a major issue that plagues Chinese government's decision-making and China's social development. At the Nineteenth National Congress, it has been clearly pointed out that the main contradiction in China's society has transformed into that between people's growing needs for good life and the unbalanced development. The important factor driving the current sharing economy in China is the serious imbalance between individuals in possession of social resources. Polarization in private possession of resources tends to continue. The society urgently needs a certain business model to ease this contradiction. Under the guidance of diversified values, people have participated in the sharing economy with various motives. Taking Didi as an example, it pushes a slogan "You drive your car, and I take a cheap ride". In this way, people benefit from the sharing economy as each can take what he needs and each can obtain its own pleasure. As to the sharing objects, they are not only physical resources that are visible and tangible, but also intangible resources such as funds, time, labor services, knowledge, skills and production 
capabilities. When the per capita possession of the society is unbalanced and the utilization rate is insufficient, the model of sharing economy emerges, as the most distinctive feature of the model of sharing economy is the temporary short-term usage right transfer of idle resources through technical means. In this way, the resource owners can receive their corresponding incomes. The emergence of shared platforms has, to a large extent, enabled many privately-owned resources to be fully utilized, and it has alleviated China's unbalanced private possession of resources by means of leasing, donation and exchange.

\section{B. Technologies Shaping the Economic System}

Internet technology eliminates information asymmetry. Before the era of the Internet of Everything, due to information asymmetry, resource demanders could not obtain effective idle resource information and use it. In the era of the Internet and the Internet of Things, platforms idle resources can be transformed into effective social resources by platforms. Idle resources can be used indiscriminately into a sense on public resources in some levels through information interaction, vertical segmentation, multilateral participation, automatic matching and multiple transactions. Network platforms are the core support of the sharing economy. By them, idle resources are efficiently configured by both suppliers and requesters to achieve the value goals of "making the best use of things" and "distributing according to need"[6]. In addition, Internet technology transforms the problem of trust among "people" into that of trust between "people and platforms" and credit construction[22]. The characteristics of individuals or organizations that are originally difficult to perceive can be transformed into standardized modules through the information integration at shared platforms and can be quickly copied. That is to say, the random face-to-face mechanism can be transformed into a standard automatic matching mechanism to ensure the beneficial results of scale.

\section{Social Culture Promoting Community Relations}

China is a nation that values socialization. The traditional economy depends on the society of acquaintances. Internet technology promotes the communities and economy that formed by strangers. By the end of June in 2018, China's Internet population reached 802 million. The society members in the Internet era belong to a variety of interconnected virtual communities. Based on interest map, geographic location and service groups, these communities usually try to absorb more Internet population. By this, highly sticky social attributes attract more netizens and increase the transaction conversion rate. Not only products or services but also individual hobbies, special experiences and feelings can be shared through social platforms. Providing a better social experience for all their participants facilitates these platforms of sharing economy to enhance the active participation of users in consumption[14]. The expansion of social networks has rapidly increased the beneficial results of scale in the sharing economy, i.e. Aggregate Value. The cost of resource allocation, use and management of such communities may be lower than the transaction cost of physical markets or that of the administrative system, increasing the benefits of the sharing economy and maintaining sustainable cost benefits[21].

\section{Challenges of The SHARING ECONOMY TO CHINA' S SOCIAL GOVERNANCE}

The sharing economy gives people more freedom, but it also brings a lot of uncertainties. It separates the right of dominion and the right to use of resources, and its characteristics of online operation make resource owners, resource users and managers not know each other or even not meet each other. Therefore, it is difficult for the traditional economic and social management model to adapt to it. The explosive growth of the sharing economy in recent years has made this challenge increasingly severe.

\section{A. Separation of Usage Right and Ownership Changing the Equity Distribution Pattern}

The sharing economy has given people more freedom, but it has also brought many uncertainties. The core of sharing economy's value creation lies in the efficient use of existing idle resources by using information technologies such as the Internet. In essence, it is the sale of some unused and remaining usage rights and the separation of the ownership and usage rights to create instant, short-term and efficient rental incomes, so it changes the traditional transaction-based equity distribution model. Under the sharing economy model, the point economic structure that everyone participates has replaced the existing block economic structure with enterprises as its main body and has profoundly involved the core issues of the property rights system, the fiscal system and the taxation system[20]. It will also impact the benefits of vested interests and trigger the conflicts between the old and new economies. For example, if the access threshold of the sharing economy is far lower than that of the traditional industry, compared to drivers working for taxi companies, traditional hotel industries and catering professionals respectively, private car drivers, individual landlords in the short-term rental sector and chefs working for a private kitchen do not need to obtain the administrative licenses and they are more often checked online by way of online registration. This triggers a lot of friction between the old and new industries.

\section{B. Participants Lacking Senses of Mission and Responsibility for Their Organizations}

Under the traditional enterprise model, the leaders or management of companies attract their employees through establishing company's vision, formulating various incentive measures to motivate and retain employees, improving employees' enthusiasm and sense of belonging. Under this model, individuals need to be responsible for their own organizations and achieve the common goals of their organizations, which means individuals need to take some responsibilities. Under the constraints of such a system, people are more likely to have a sense of responsibility and a sense of mission. For example, the government agencies distribute taxi licenses to companies. The companies subcontract their operating rights to various taxi companies which have a contractual relationship with drivers. The identity of a taxi driver is only one employee of a taxi company.

Under the sharing economy model, the organizational structure is no longer stable and the impact of an organization on individuals is reduced to a low level. This will only give 
individuals a temporary collective feeling. When individuals are affected by the group atmosphere for a long time, they will gradually lose their sense of responsibility and sense of mission. In this case, it is difficult to ensure their service quality. After the emergence of Uber, Didi and other models of sharing economy, the links related to licenses, companies, management and drivers under the traditional economic model, are all completed by software companies. Under this individualized and decentralized model of sharing economy, each driver on the platform is a free participant who assumes partial obligations and has corresponding rights and interests. Under this model, the contractual relationship between drivers and platforms is relatively loose and simple. Working or not is all of drivers' spontaneous behaviors. With the help of convenient conditions from the platform, drivers can easily launch a strikelike collective boycott against the company. Such sudden collective strikes have caught platform companies and markets unprepared. In order to avoid such large-scale strikes, a responsible officer of Uber once said, for Uber, a model of sharing economy. It only hopes to provide everyone with an opportunity for a flexible part-time job and does not encourage all the drivers to become full-time drivers.

\section{The Division of Responsibilities Between Platforms, Service Providers and Customers is Not Clear and Related Legal Provisions Are Not Available}

As a new business model of sharing economy, there is no clear law for it in China. As suppliers, requesters and platform companies have no perfect legal basis for their respective responsibilities, obligations and rights in such transaction process, problems and disputes often arise[15]. For example, the sharing economy provides a large number of employment opportunities and promotes the scale development of hidden employment and freelancers. However, such non-traditional labor relations are divorced from the social security safety net. It is difficult for the current various social security systems to cover them, so it is difficult for laborers to safeguard their rights in event of labor disputes. An institutional solution is needed for this new type of labor relationship which has gradually become a new trend in employment. Who should be responsible for the car insurance, the car depreciation, etc. during the service period of providers on such online traffic platforms? How to define the rights and interests of the platform customers as both suppliers and requesters are unfamiliar individuals? Who should be responsible for the loss of equity? How to divide the rights and responsibilities between platforms and service providers? The development of the sharing economy requires suppliers, requesters and platform companies at the same time. As the relevant laws and policies are not available or inappropriate[10], there is no legal basis for the responsibilities, obligations and rights of the three parties involved in the transaction process.

\section{ADVICE ON GOVERNANCE OF THE SHARING ECONOMY}

The idea of "perfecting and developing the socialist system with Chinese characteristics and modernizing the country's governance system and governance capacity" was put forward at the Third Plenary Session of the 18th CPC Central Committee. For the first time, "management" was replaced with "governance" and became the party's governing philosophy in the all-round deep reform period. As the overall goal of comprehensively deepening reforms, this means that the party' s governing philosophy has transformed from topbottom "management" by the government to governance which combines the government' s top-bottom management and the society' s bottom-top management, and its implementation has transformed from a single government' s subject to a society' $\mathrm{s}$ multiple subjects[7]. In terms of tools, the governance is characterized with adding folk rules to institutional policies, transforming from control to service and from regulation to collaboration, so as to achieve the shared governance by government and people. This is obviously a major theoretical innovation in socialism with Chinese characteristics. Governance has become the ruling concept and the strategy for ruling the country in the new era of deep reform. After the text edit has been completed, the paper is ready for the template. Duplicate the template file by using the Save As command, and use the naming convention prescribed by your conference for the name of your paper. In this newly created file, highlight all of the contents and import your prepared text file. You are now ready to style your paper.

\section{A. Improve the Relevant Laws and Policies}

The model of sharing economy is still a new thing in China and the legal framework of government's governance generally lags behind the market development. Due to the asymmetry in information and weak supervision, "failures in the market mechanism" may occur in the trading market of the sharing economy. Ezubao, one of the largest and best-known P2P lenders, was exposed as a Ponzi scheme in which 900,000 users lost 50 billion yuan ( $\$ 7.6$ billion). Therefore, the Government needs to improve the legal system, formulate relevant policies and regulations, and regulate the behaviors of platform companies to ensure the personal and property security of individual participants and to prevent the occurrence of opportunistic behaviors, so that there are laws to follow for the economic behaviors under the model of sharing economy and there is a good social order for the sharing economy to develop.

Since 2008, China' s relevant ministries and commissions have respectively issued some policy documents related to the sharing economy[8], which cover the issues of current network information security under the model of sharing economy, network economic market order and behavior, credit construction and unbalanced regional development. The vertical legal relations involving market access and taxation of operators are mainly the application of the existing traditional fields of law to the model of sharing economy, e.g. in terms of the market access, the taxation system and the invoice system at the operational level of enterprises. However, it is necessary to continue to study and improve new laws and policies. Hand Formula can be used as a theoretical basis for dividing and 
formulating the legal responsibilities of the various entities involved in the economy.

\section{B. The Government Can Join Hands with the Platforms to Supervise the Individuals on Such Platforms}

Effective supervision should be layered. The Government's direct management of individuals not only ignores the role of the network platforms as the most effective coordinating body, but also allows the Government to directly face numerous inconveniences and conflicts. This will greatly increase the burden of public services and undermine the Government's governance prestige due to constant supervision setbacks. The platform companies that undertake private investments have a lot more enthusiasm, knowledge, experience and management tools than the Government in safeguarding platform order and credibility under the open competition environment. In addition, they have the ability to directly manage individuals on their platforms.

\section{Establish a Personal Credit Rating System}

The model of sharing economy is a business model that is highly dependent on credit. It requires a strict credit rating system that can guarantee both parties to make secure transactions. The activity of the sharing economy is closely related to the establishment and improvement of the credit rating. The healthy development of sharing economy will also increase social trust. Therefore, it is necessary to establish a credit rating system covering both sides of transactions to ensure that credit reference can be provided before, during and after the transaction. It will provide a safe trading environment for the sharing economy. In this regard, Alibaba Group has made a good attempt when its Xianyu App launched a trading community called Fish Pond, which is divided based on geographical information. Buyers and sellers can actively socialize in the Fish Pond. Through long-term daily social networking, a transaction can turn from a transaction between strangers to a transaction between more reliable acquaintances.

\section{Encourage Social Supervision and Cooperative Governance}

At present, many new industries such as the equity crowdfunding industry are walking in the gray zone of supervision. Some innovation practices may have to meet some unreasonable institutional requirements. For example, enterprises engaged in Internet education are required to provide an offline teaching site. Otherwise, they will not be approved. The sharing economy has brought about a clear impact on the traditional regulatory model, and the original legal supervision may be improper, ineffective or inadequate for it. In the early development stages of sharing economy, it is inappropriate to introduce many specific rigid laws and regulations for it without identifying its advantages and disadvantages and its overall situation. The regulatory objectives for the sharing economy should be diversified (solving employment, raising tax revenue, prospering the economy, being of sustainable development and of innovation entrepreneurship, etc.). And the regulatory bodies and regulatory instruments should also be diversified. It is suggested to mobilize platforms, social institutions, consumers, providers and other social forces to establish an interactive and open multi-agent social evaluation and comprehensive governance system to make up for the lack of legal supervision, so that each agent can find an evaluation basis and key evidence before, during and after its sharing, Information technology and big data can be fully utilized in government regulation, so that everyone' s behavior can be traced on the Internet. When a dispute arises, the truth can be restored to guide the stakeholders of sharing economy to fulfill their social responsibilities. This will also enhance the public regulatory awareness. In addition, commercial insurance can also be introduced to provide insurance services for the parties involved in the sharing economy.

\section{E. Strengthen the Social Security System}

The ILO (International Labour Organization) survey shows that more and more people have taken more flexible employment patterns and that the full-time long-term forms of employment are changing. The research result from the perspective of social security shows that $80 \%$ of the workers with long-term employment contracts, only $50 \%$ of the workers with flexible employment, and only $16 \%$ of self-employed workers have participated in social security. Therefore, it is suggested that the Government further improve the social insurance system so as to cover freelancer groups and entrepreneurial groups. Only relieving from such worries, can they take the risk to start their businesses and make innovations.

\section{SUMMARY}

With the rapid development of Internet information technology, it is inevitable that the traditional economic model will decline and the model of sharing economy will further develop. However, at this stage, the model of sharing economy is still in its infancy and all sectors of society should calmly consider the possible problems with this business model, attach importance to and actively cope with them by policy formulation, supervision methods, macro-control, platform management, credit construction and social governance. Undoubtedly, the scientificalness of government management lies in whether it can promote the orderly development of emerging industries and the new economy. The Government needs to use innovative management methods, actively explore more management and governance methods to create a winwin environment for emerging industries and new economic models.

\section{ACKNOWLEDGMENT}

Thank all my teammates and thanks for Zhejiang Zheshang Research Center of Zhejiang Philosophy and Social Science Planning Project (16JDGH122). 


\section{REFERENCES}

[1] Belk, R., (2007). Why not share rather than own. Annals of the American Academy of Political and Social Science, 611(1), 126-140.

[2] Belk, R., (2014). You are what you can access: Sharing and collaborative consumption online. Journal of Business Research, 67(8), 1595-1600.

[3] Benkler Y., (2002). Coase's penguin, or, linux and the nature of the firm. Yale Law Journal, 112(32), 369-446.

[4] Chen, Y., (2009). Possession and access: Consumer desires and value perceptions regarding contemporary are collection and exhibit visits. Journal of Consumer Research, 35(6), 925-940. (In Chinese)

[5] Coase, R. H., (1937). The nature of the firm. Economica, 4(16), 386-405.

[6] Chenghui D., (2016). Shared Economy: Theory and Reality. Journal of Guangdong University of Finance \& Economics, 31(5), 4-15. (In Chinese)

[7] Dongdong F., (2014). From Management to Governance-A Review of Social Management in the past decade. Journal of Southwest Jiaotong University(Social Sciences), 2014(5), 128-132. (In Chinese)

[8] Fanxin M., (2015). Network Transaction Market Governance under the Sharing Economy Model: Example of Taobao Platform. Journal of Reform, 2015(12), 104-111. (In Chinese)

[9] Felson, M., \& Spaeth J., (1978). Communitive structure and collaborative consumption. American Behavioral Scientist, 21(4), 614624.

[10] Guowei Z., Hongshan L., \& Li Z., (2018). Enhancing the development of sharing economy to mitigate the carbon emission: a case study of online ride-hailing development in China. Journal of Natural Hazards, 91(2), 611-613.

[11] Hamari, J., Sjöklint, M., \& Ukkonen, A., (2016). The sharing economy: why people participate in collaborative consumption. Journal of the Association for Information Science \& Technology, 67(9), 2047-2059.

[12] Liansheng, Z., (2017). Sharing Economy: Essence, Mechanism, Models and Risks, Journal of International Economic Review, 2017(6), 45-69. (In Chinese)

[13] Qiang M., (2016). Development Status, Bottlenecks and Countermeasures of Sharing Economy in China. Journal of Modern Economic Research, 2016(10), 20-24. (In Chinese)

[14] Qian, L. (2018, March 16). The connotation and characteristics of shared Traffic. China Transportation Review, Retrieved September 13, 2018, from http://kns.cnki.net/kcms/detail/11.1197.U.20171201.1126.002.html. (In Chinese)

[15] Qian Y., Ying L., Xiping Y., Huaping W., Miao G., \& Bing Z., et al. (2017). Study on Sports Industrial Share Economy in the Era Internet Plus. Global Journal of Human-Social Science: H Interdisciplinary, 17(1), 25-28.

[16] Rifkin, J. (2014). The zero Marginal Cost Society: The Internet of things, the Collaborative Commons, and the Eclipse of Capitalism. New York, NY: St. Martin's Press.

[17] Robin Chase. (2015). Sharing Economy: Reconstructing the New Model of Future Business. Hangzhou, Zhejiang: Zhejiang People's Publishing House.

[18] Rogers, B. (2015). The social costs of uber. Social Science Electronic Publishing.

[19] Shirky C. (2011). Cognitive Surplus: How Technology Makes Consumers into Collaborators. London, UK: Penguin Group.

[20] Shupei Y., (2015). China's sharing of the necessary conditions for Economic Development and its Sustainable Development. China Collective Economy, 2015(13), 16-18. (In Chinese)

[21] Xuecheng Y., \& Ke T., (2016). Research on dynamic value creation in the context of shared economy: a case study of Travel platform. Management Review, 28(12), 258-268. (In Chinese)

[22] Yue P., (2016). Legal Regulation of shared economy: a case study of Internet Private car. Administrative Law Review, 2016(1), 117-131. (In Chinese)

[23] Yu-yuan J., (2015). Policy Trajectory, Operation Mode and Trend of Network Economy. Journal of reform, 2015(1), 55-65. (In Chinese) 